\title{
ERRATUM
}

\section{Erratum to: Metabolic Responses of Tea (Camellia sp.) to Exogenous Application of Ascorbic Acid}

Amarchand Chordia Murugan, Jibu Thomas, Raj Kumar Rajagopal, Abul Kalam Azad Mandal

(C) Korean Society of Crop Science and Springer 2012

Erratum to: J. Crop Sci. Biotech. 15(1): 53-57

DOI No. 10.1007/s12892-011-0047-x

Short title in page 56, "Molecular Marker for Drought Tolerance in Wheat" was incorrect. The correct short title in page 56 should be as follows:

"Metabolic Response of Tea to Exogenous Ascorbic Acid".

We apologize to readers for the mistake.

The online version of the original article can be found at http://www.springerlink.com/content/u281525821287w33/fulltext.pdf.

A. C. Murugan $(\bowtie)$

Faculty of Industrial Sciences \& Technology, Universiti

Malaysia Pahang, LebuhrayaTun Razak, 26300, Gambang,

Kuantan, Pahang Darul Makmur, Malaysia

E-mail: amarchand.chordia@gmail.com

Tel: +60-0108108396

J. Thomas

Department of Biotechnology, Karunya University, Coimbatore 641114, India

R. K. Rajagopal

Plant Physiology and Biotechnology Division, UPASI Tea

Research Foundation Tea Research Institute, Nirar Dam BPO,

Valparai 642 127, Coimbatore, India

A. K. A. Mandal

School of Biosciences \& Technology, VIT University, Vellore

632014, India 